\title{
Biodistribution of boron after intravenous 4-dihydroxyborylphenylalanine-fructose (BPA-F) infusion in meningioma and schwannoma patients: A feasibility study for boron neutron capture therapy
}

\section{MARTTI KULVIK* ${ }^{* 1,2}$, MERJA KALLIO ${ }^{1}$, JUHA LAAKSO $^{1,3}$, JYRKI VÄHÄTALO $^{1}$, RAINE HERMANS ${ }^{4}$, EIJA JÄRVILUOMA ${ }^{5}$, ANDERS PAETAU ${ }^{6}$, MERJA RASILAINEN ${ }^{5}$, INKERI RUOKONEN ${ }^{1}$, MATTI SEPPÄLÄ ${ }^{7}$ AND JUHA JÄÄSKELÄINEN ${ }^{8}$}

Departments of Neurology ${ }^{1}$ Neurosurgery ${ }^{7}$, and Pathology ${ }^{6}$, and HUCH Pharmacy ${ }^{5}$, Helsinki University Central Hospital, Helsinki; The Research Institute of the Finnish Economy ${ }^{2}$, Helsinki; TUKES, Finnish Safety and Chemicals Agency ${ }^{3}$, Helsinki; Helsinki; Aalto University School of Economics ${ }^{4}$, Helsinki Neurosurgery ${ }^{8}$, Institute of Clinical Medicine, Faculty of Medicine, University of Kuopio

*Corresponding author, e-mail: martti.kulvik@etla.fi

Running head: Boron distribution in NF2, schwannoma and meningioma Key words: BNCT, NF2, meningioma, schwannoma

This work was sponsored by the Department of the Army (Grant No. DAMD17-00-1-0545). The U.S. Army Medical Research Acquisition Activity, 820 Chandler Street, Fort Detrick MD 217025014, USA, is the awarding and administering acquisition office.

\section{Abstract}

We studied the uptake of boron after $100 \mathrm{mg} / \mathrm{kg}$ BPA infusion in three meningioma and five schwannoma patients as a pre-BNCT feasibility study. With average tumour-to-whole blood boron concentrations of 2.5 , we discuss why BNCT could, and probably should, be developed to treat severe forms of the studied tumours. However, analysing 72 tumour and 250 blood samples yielded another finding: the plasma-to-whole blood boron concentrations varied with time, suggesting that the assumed constant boron ratio of 1:1 between normal brain tissue and whole blood deserves reassessment.

Boron neutron capture therapy (BNCT) has been administered to patients with glioma and head and neck cancer in Finland using the amino acid derivative borono-phenylalanine as the boron carrier (Kulvik et al., 2003). To determine whether BNCT could have an effect on meningiomas and schwannomas, we initiated a study of feasibility for the use of BNCT to treat severe forms of either sporadic or NF2-related meningiomas and schwannomas. To this end, we studied the uptake of boron after BPA infusion in these patient groups: five schwannomas and three meningiomas. 
Meningiomas and schwannomas are typically histologically CNS tumours, which are most often clearly demarcated from the brain and thus accessible to microsurgery and stereotactic radiotherapy. However, the tumours can also be numerous and in surgically difficult locations (Philippon, 2003), particularly in patients with neurofibromatosis II (NF2). Furthermore, the poor general condition of the patient can make these tumours inoperable. Consequently, new therapeutic modalities are needed for the not insignificant proportion of these patients.

Boron neutron capture therapy (BNCT) is an experimental neutron activated pharmacotherapy for tumours (Gupta et al., 2003; Locher, 1936). The principle of BNCT is attractive as the energy of the radiation is so high that tumour radioresistance does not play a significant role. Additionally, the surrounding tissues receive only small amounts of radiation if the basic requirements of BNCT are met including: sufficiently high and selective boron concentrations in the tumour and a sufficient amount of thermal neutrons to the tumour (Gupta et al., 2003).

In BNCT, the boron-10 atoms are activated by thermal neutrons and emit locally short range (10-20 $\mu \mathrm{m})$, very high-energy alpha radiation corresponding to the cell diameter and high energy lithium nuclei. In practice, the effectiveness of BNCT is mainly dependent on the boron concentration in various areas of the tumour, and the safety of the treatment depends on respective boron concentrations in the surrounding tissues. As modern nuclear technology has solved major problems with the delivery of neutron irradiation, the present challenge is to generate a sufficient and selective boron uptake in the target tissue.

\section{Materials and Methods}

The study protocol was approved by the ethical committee of Ophthalmology, Otorhinolaryngology, Neurology and Neurosurgery of the Joint Authority for the Hospital District of Helsinki and Uusimaa and by The Surgeon General's Human Subjects Research Review Board, Office of Regulatory Compliance and Quality, Department of the Army, Office of The Surgeon General, Department of Defence, USA. The patients voluntarily participated in the study after signing an informed consent. All parts of this work are in compliance with the requirements of the World Medical Association Declaration of Helsinki 1995 and revision of 2000. Appropriate notification of a clinical trial on medicinal products in human subjects (form 723) with appendices was presented to the Finnish Medicines Agency (www.fimea.fi) prior to initiation of the study. 
BPA-F infusion. BPA was purchased from Katchem Ltd. (Kulvik et al., 2003). The BPA-F solution was prepared in the hospital pharmacy of $\mathrm{HUCH}$, Helsinki. The solution was prepared at a concentration of $30 \mathrm{~g} / 1(0.14 \mathrm{M})$ by combining BPA with a 10\% molar excess of fructose in sterile water. The detailed procedure was previously described (Kulvik et al., 2003). The solution was intravenously administered via an IVAC ${ }^{\text {TM }}$ infusion pump using Optiva $2^{\text {TM }}$ or Venflon Insyte vein cannulas. The infused amount was $100 \mathrm{mg}$ BPA per kilogram of body weight (bw), with an infusion time of one hour. The total volume of infusions varied between 217 and $280 \mathrm{ml}$, corresponding to BPA doses of 6.5 and $8.4 \mathrm{~g}$, respectively.

The infused dose of $100 \mathrm{mg}$ BPA per kilogram body weight is clearly below the more standard dose of $300 \mathrm{mg}$ BPA per kilogram body weight used in clinical BNCT. As the patients could not be offered BNCT or any other potential benefits from their participation, we wanted to minimize our patients' exposure to potentially harmful infusion but retain boron concentrations for sufficiently reliable measurements. If this initial feasibility study proved promising, it would justify a trial with clinical doses of either $300 \mathrm{mg} / \mathrm{kg}$ or $450 \mathrm{mg} / \mathrm{kg}$.

Patients. The BPA-F solution was administered in conjunction with the intracranial tumour operation to eight patients: four women and four men. The patients had a symptomatic, radiologically diagnosed convexity meningioma or vestibular schwannoma. Otherwise, the patients were healthy and did not suffer from fructose intolerance (Laakso et al., 2003).

Patients with symptomatic cardiac insufficiency, liver or renal disease, pregnancy or lactation, prior operations or radiotherapy to the brain or prior chemotherapy for any systemic cancer were excluded. The histology of the tumour was confirmed from the operative samples: three patients had a meningioma and five patients had a schwannoma. Four of the schwannomas were sporadic, and one of the schwannomas was operated on a patient with NF2 (Table 1).

A pre-operative neurological examination was performed. Routine pre-operative laboratory tests were taken before the onset of infusion. During the infusion, the patients were continuously monitored through a three lead electrocardiogram device; blood pressure and heart rate were measured every hour, and clinical symptoms were regularly surveyed. Monitoring was continued until the onset of operation, and during operation thorough monitoring was performed as part of neuroanaesthesia. After operation, the patients remained in the post-operative intensive care unit for 
a minimum of 24 hours. A post-infusion neurological examination was performed approximately two days after operation.

\section{Tumour samples and boron measurement.}

The tumours were sampled in two ways depending on tumour type. The three meningiomas were extirpated as one lump at one specific time point and immediately sent in dry ice to the neuropathologist. The samples were obtained by dividing the extirpated tumour into four regions: 1 . the dural stem, 2. the tumour region close to the stem and major feeding blood vessels, 3. centre of the tumour, and 4. close to the surface opposite to the stem and the blood supply.

To control for possible histological heterogeneity (Coderre et al., 1998), we divided the tissue samples into two halves whenever feasible, with one part of the sample analysed by the neuropathologist and the other part deep-frozen and analysed later for the boron concentration.

The five vestibular schwannomas were removed piecemeal during a lengthy operation, with the last sample taken between 150 and 240 minutes after removal of the first portion. Whenever feasible, the samples were divided in the operation theatre so that one part of a sample was sent to the neuropathologist, and the adjacent part was deep-frozen for later measurement of the boron concentration.

Altogether, 72 tumour samples ranging in size from 15 to 274 milligrams were analysed for their boron concentration. The number of samples from one single tumour varied from 6 to 17. Tumour tissue pre-treatment consisted of wet-ashing with nitric acid. The boron concentrations from the pretreated samples were determined using a Perkin-Elmer 3200 DV Inductively Coupled PlasmaAtomic Emission Spectrometer (ICP-AES), The Perkin-Elmer Corporation, Norwalk, Connecticut, USA.

\section{Blood samples and boron measurement.}

Venous blood samples for the measurement of boron concentrations were taken before the onset of BPA-F infusion, at 30-minute intervals during infusion, and thereafter every twenty minutes for 5 hours. When feasible, final samples were taken at 8 and 24 hours after the onset of infusion. Blood 
leukocytes, erythrocytes, haemoglobin, thrombocytes, C-reactive protein, creatinine, alanine amino transferase, and gamma glutamyl transferase were monitored for the safety of the patients.

The blood samples for the analysis of boron were taken in Vacuette ${ }^{\mathrm{TM}}$ vacuum tubes in pairs, at 2 $\mathrm{ml}$ each. The blood from one tube was transferred into a cryogenic vial as a whole-blood sample; the other tube was centrifuged after pre-treatment. Blood sample pre-treatment consisted of protein removal with trichloroacetic acid by a method described earlier (Laakso et al., 2001). The boron concentrations were determined using a Perkin-Elmer 3200 DV Inductively Coupled PlasmaAtomic Emission Spectrometer (ICP-AES)

The authors processed all samples within 20 minutes in the hospital laboratory and thereafter stored the samples at $-80^{\circ} \mathrm{C}$. The possible pre-infusion presence of detectable boron or boron contamination from the Vacuette tubes or cryogenic vials was excluded by using the pre-infusion blood samples as controls.

\section{Data analysis}

Blood and tissue boron concentration data were fitted using WinSaam Ver 2.0 (National Institute of Health, USA) to construct curves showing the boron concentration as a function of time. As tumour samples were taken at irregular intervals and time points, the respective blood concentrations were estimated with linear extrapolation from the two closest blood samples. Blood samples were taken at 20-minute intervals, and the time distance between tumour samples and the closest blood sampling never exceeded ten minutes.

A regression analysis (ordinary least square) was performed with the whole data set. The variable "Time after onset of infusion" was log-transformed due to a long tail of data points skewed to the right, as blood samples were collected up to 24 hours after the onset of infusion.

\section{Results}

The tumour boron concentrations were always higher than the respective whole blood boron concentrations, indicating that all three meningiomas and five schwannomas took up boron after BPA-F infusion, even after small infused amounts; however, the tumour-to-blood ratios were highly 
variable, ranging from 1.0 to 6.8 . Table 1 shows the mean tumour-to-blood and tumour-to-plasma ratios for each patient.

Table 1. Gender, age, tumour histology, tumour size, and mean tumour-to-blood and tumour-toplasma ratios, as well as the respective ranges, for all eight patients.

\begin{tabular}{|c|c|c|c|c|c|c|}
\hline Patient & Gender & $\begin{array}{l}\text { Age } \\
\text { yrs }\end{array}$ & $\begin{array}{l}\text { Tumour } \\
\text { histology }\end{array}$ & $\begin{array}{l}\text { Tumour } \\
\text { size, mm } \\
\text { (weight, } \\
\text { grams) }\end{array}$ & $\begin{array}{l}\text { Tumour -to- } \\
\text { blood } \\
\text { Mean (Range) }\end{array}$ & $\begin{array}{l}\text { Tumour -to- } \\
\text { plasma } \\
\text { Mean (Range) }\end{array}$ \\
\hline Patient 1 & $\mathrm{~F}$ & 58 & $\begin{array}{l}\text { Meningioma } \\
\text { G1, uniform }\end{array}$ & $\begin{array}{l}30 \times 20 \times 13 \\
(3.15 \mathrm{~g})\end{array}$ & $\begin{array}{c}\mathbf{6 . 3} \\
(5.4-6.8)\end{array}$ & $\begin{array}{c}\mathbf{6 . 4} \\
(5.5-7.0)\end{array}$ \\
\hline Patient 2 & $\mathrm{~F}$ & 54 & $\begin{array}{l}\text { Meningioma } \\
\text { G1, fairly } \\
\text { uniform }\end{array}$ & $\begin{array}{l}25 \times 23 \times 24 \\
(4.1 \mathrm{~g})\end{array}$ & $\begin{array}{c}\mathbf{2 . 5} \\
(1.3-4.1)\end{array}$ & $\begin{array}{c}\mathbf{2 . 2} \\
(1.1-3.6)\end{array}$ \\
\hline Patient 3 & $\mathrm{M}$ & 70 & $\begin{array}{l}\text { Meningioma } \\
\text { G1, } \\
\text { angiomatotic, } \\
\text { fairly uniform }\end{array}$ & $\begin{array}{l}20 \times 20 \times 15 \\
(4.4 \mathrm{~g})\end{array}$ & $\begin{array}{c}\mathbf{2 . 2} \\
(1.7-3.1)\end{array}$ & $\begin{array}{c}\mathbf{1 . 5} \\
(1.2-2.2)\end{array}$ \\
\hline Patient 4 & $\mathrm{~F}$ & 34 & $\begin{array}{l}\text { Schwannoma } \\
\text { G1, uniform }\end{array}$ & 14 (diam) & $\begin{array}{c}\mathbf{3 . 3} \\
(2.6-3.9)\end{array}$ & $\begin{array}{c}\mathbf{3 . 2} \\
(2.3-4.1)\end{array}$ \\
\hline Patient 5 & $\mathrm{M}$ & 44 & $\begin{array}{l}\text { Schwannoma } \\
\text { G1, uniform }\end{array}$ & 12 (diam) & $\begin{array}{c}\mathbf{2 . 2} \\
(1.7-2.9)\end{array}$ & $\begin{array}{c}\mathbf{1 . 4} \\
(1.0-1.7)\end{array}$ \\
\hline Patient 6 & $\mathrm{~F}$ & 36 & $\begin{array}{l}\text { Schwannoma } \\
\text { G1, uniform }\end{array}$ & 11 (diam) & $\begin{array}{c}\mathbf{1 . 3} \\
(1.0-1.6) \\
\end{array}$ & $\begin{array}{c}\mathbf{0 . 9} \\
(0.8-1.2) \\
\end{array}$ \\
\hline Patient 7 & $\mathrm{M}$ & 60 & $\begin{array}{l}\text { Schwannoma, } \\
\text { G1, scattered } \\
\text { fibrosis }\end{array}$ & 21 (diam) & $\begin{array}{c}3.2 \\
(1.8-5.1)\end{array}$ & $\begin{array}{c}\mathbf{2 . 7} \\
(1.6-4.4)\end{array}$ \\
\hline Patient 8 & $\mathrm{M}$ & 24 & $\begin{array}{l}\text { Schwannoma } \\
\text { (NF2) } \\
\text { G1, slightly } \\
\text { nodular }\end{array}$ & 17 (diam) & $\begin{array}{c}1.9 \\
(1.5-2.4)\end{array}$ & $\begin{array}{c}\mathbf{1 . 5} \\
(1.2-1.9)\end{array}$ \\
\hline
\end{tabular}

Legend: M (male), F (female); G1 (tumour grading G1: well differentiated, low grade); NF2 (neurofibromatosis type II); diam (diameter of tumour)

As indicated earlier, the tissue samples were divided into two halves with one half being analysed for boron concentration and the adjacent half being checked for histological appearance relative to the control for any possible histological heterogeneity. All study samples showed a uniform histological appearance within the same tumour (Table 1).

The mean tumour to blood ratio for our analysed 72 samples was 3.8, with a SD of 1.5 and a range from 1.0 to 6.8. Excluding one outlier, a meningioma with a very high ratio of 6.3 , the mean was still 2.5 and the SD was 0.8 -values fully comparable with results accepted as sufficient for the BNCT treatment of glioblastoma multiforme and locally recurred head and neck cancer (Kankaanranta et al., 2011a; Kankaanranta et al., 2011b; Laramore and Spence, 1996). 
The whole blood, plasma boron, and tissue sample boron concentrations as a function of time from the onset of infusion were presented for three meningioma and five schwannoma patients in Figures 1.a to 1.h. Considerable variation can be observed between patients, tumour types and even within the same tumour. One meningioma (Patient 1) showed a strikingly high tumour-to-blood ratio with a rather homogenous distribution: tumour-to-blood ratio 6.3, range 5.4-6.8, and a total tissue boron concentration between 25 and $30 \mathrm{mg} / \mathrm{kg}$ (Figure 1.a and Table 1). One schwannoma (Patient 7) had a mean tumour-to-blood ratio of 3.2 and a range of $1.8-5.1$; the total tissue boron concentrations varied from 11.9 to over $21 \mathrm{mg} / \mathrm{kg}$ within time points closer than 30 minutes from each other (Figure 1.g and Table 1). The data also indicated that the ratio between whole blood and plasma boron levels changed with time.

\section{Patient 1, meningioma}

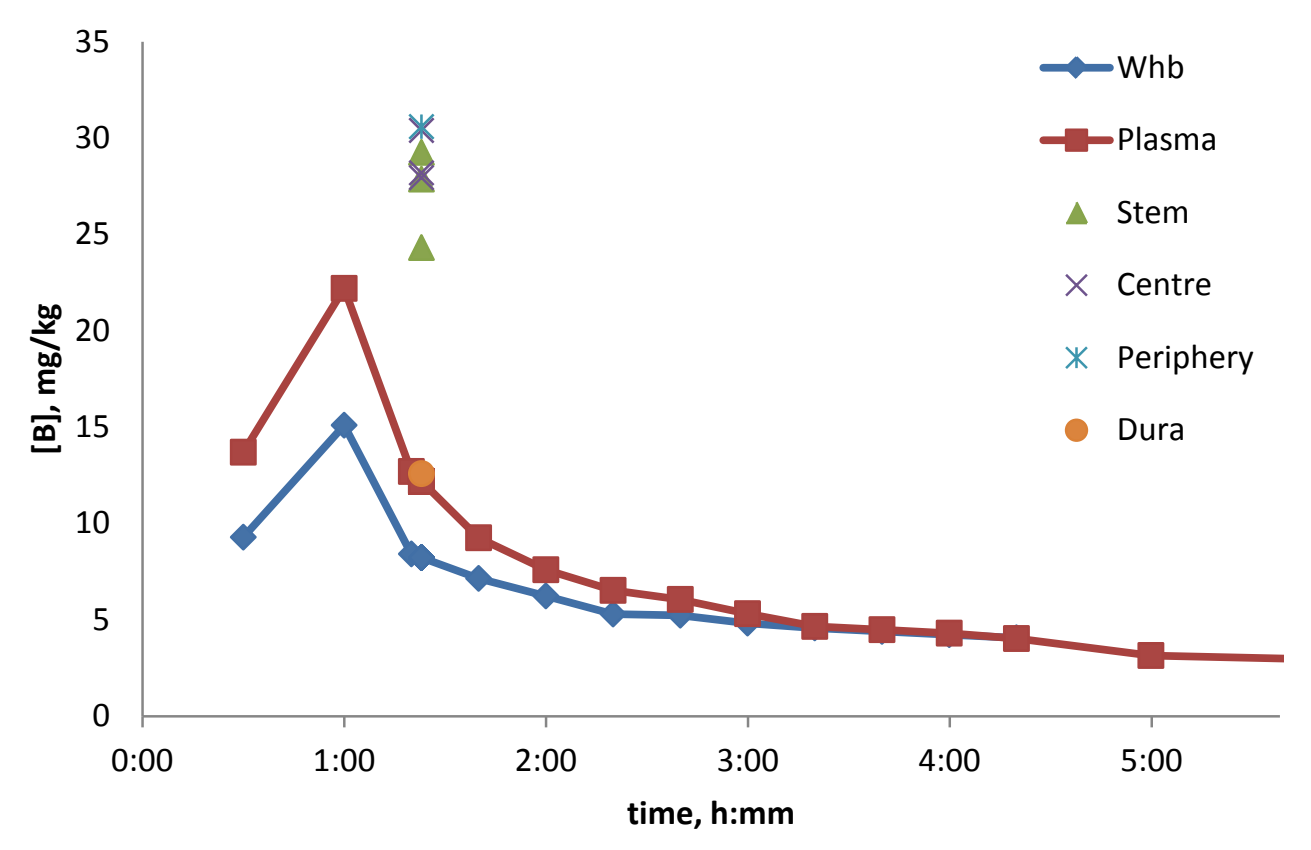

1.a. 


\section{Patient 2, meningioma}

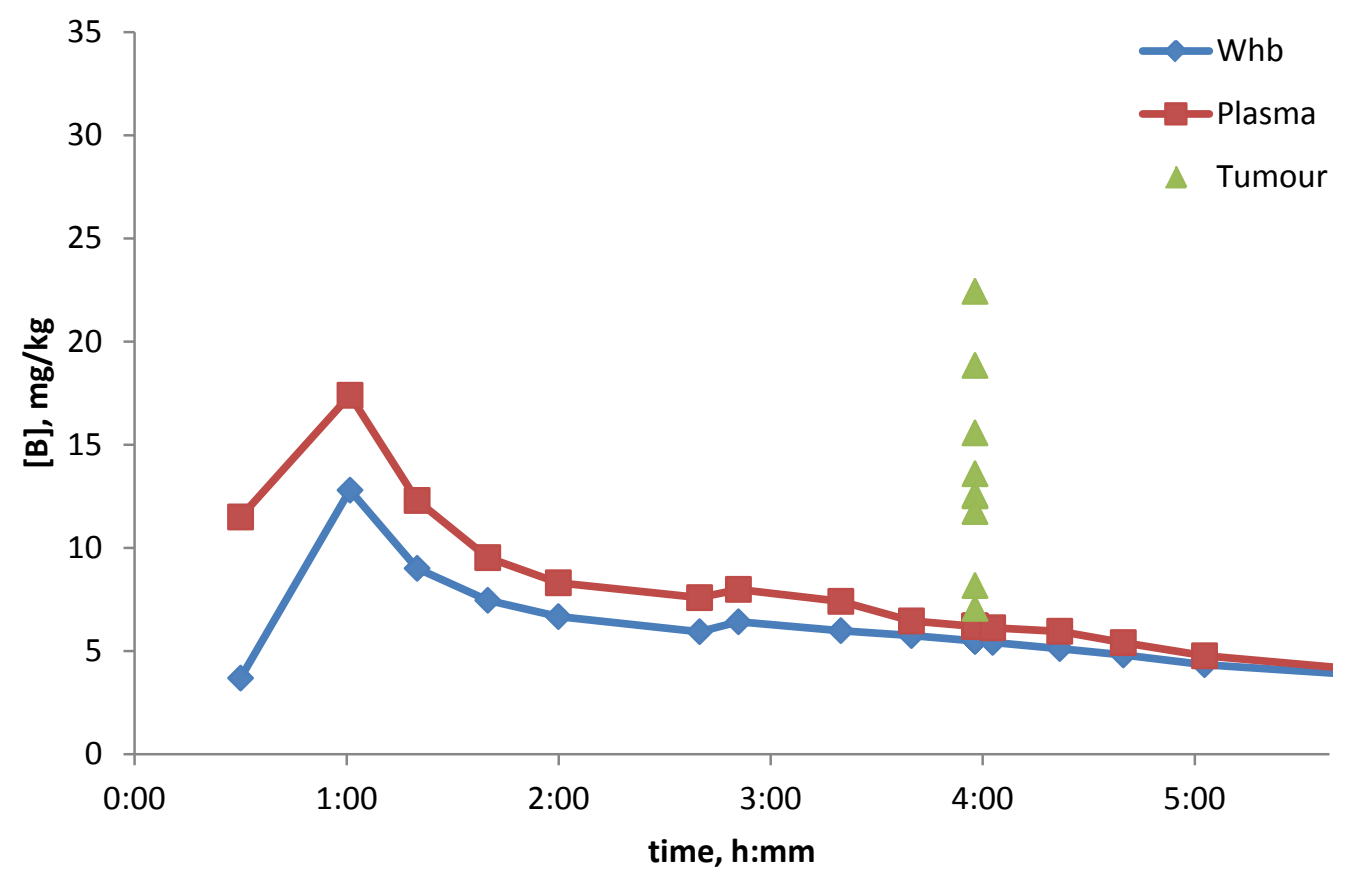

1.b.

Patient 3, meningioma

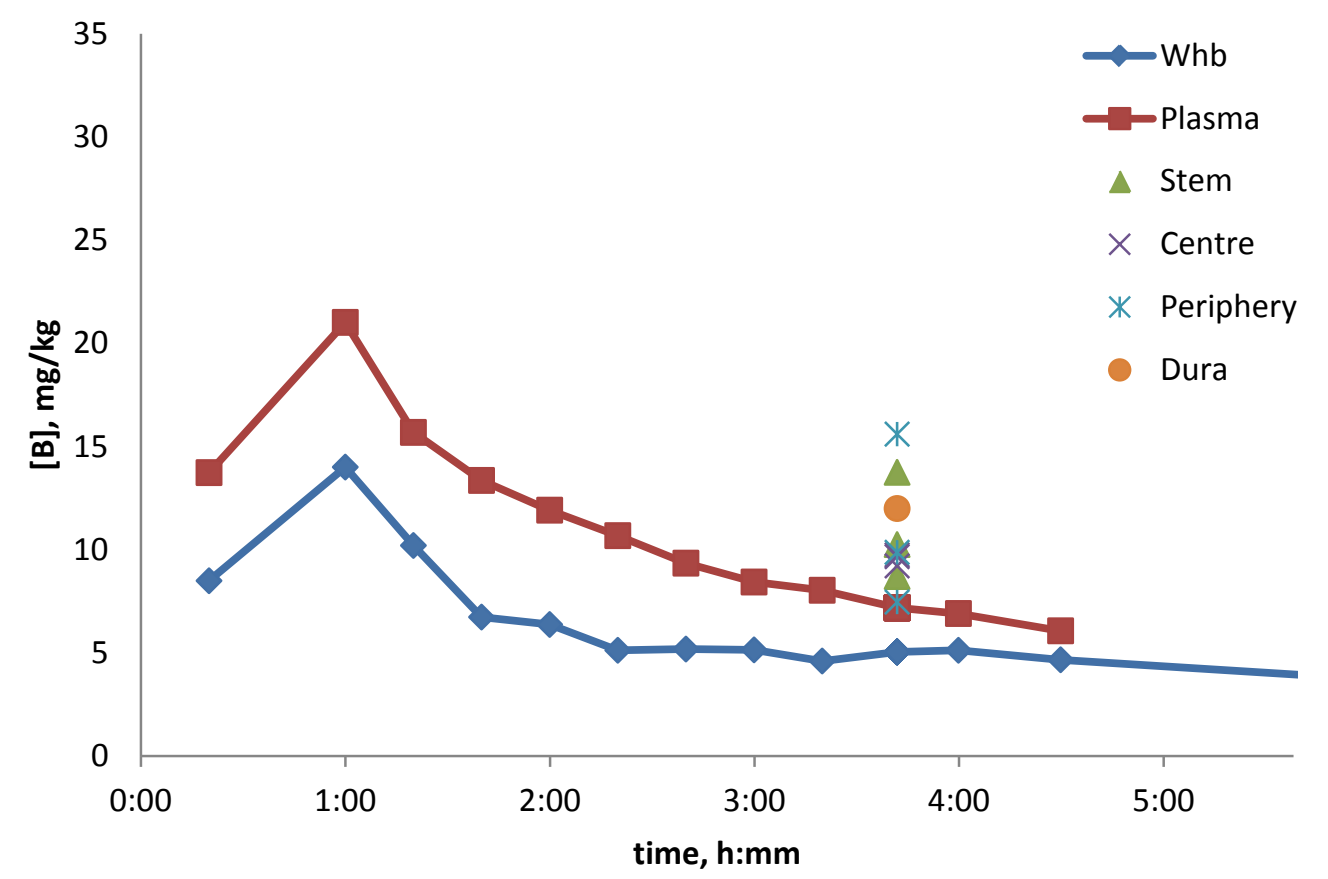

1.c. 
Patient 4, schwannoma

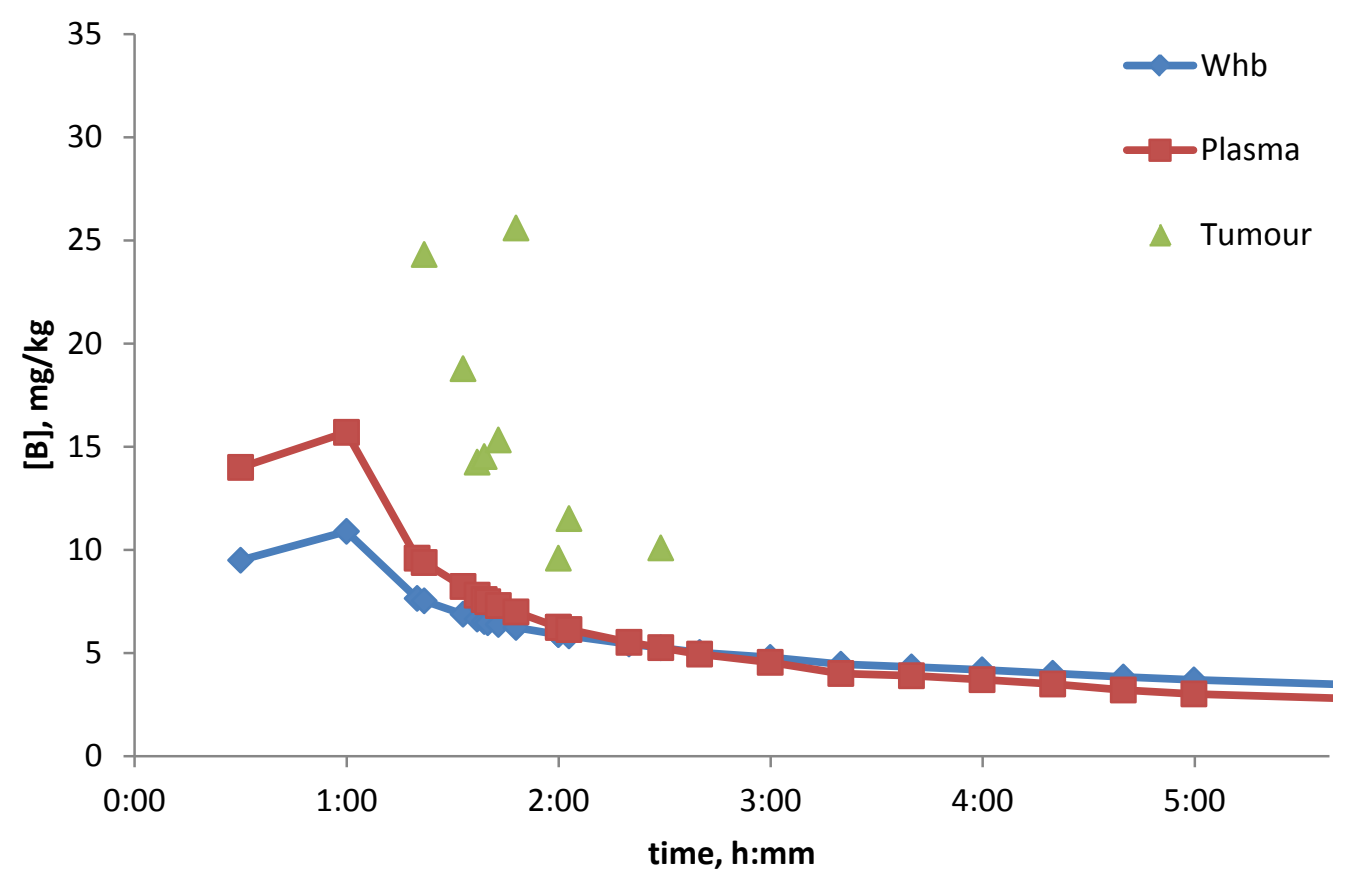

1.d.

Patient 5, schwannoma

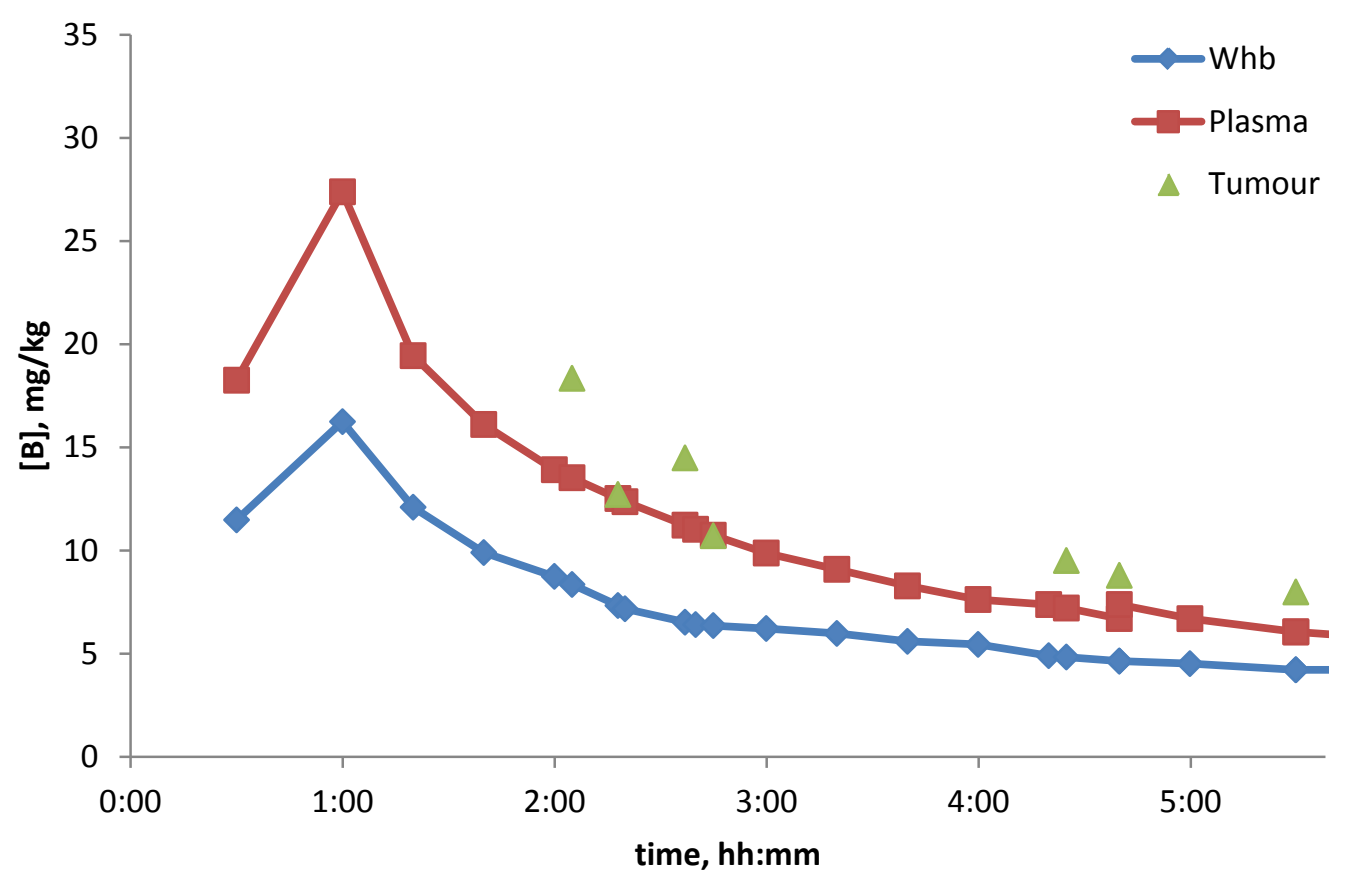

1.e. 
Patient 6, schwannoma

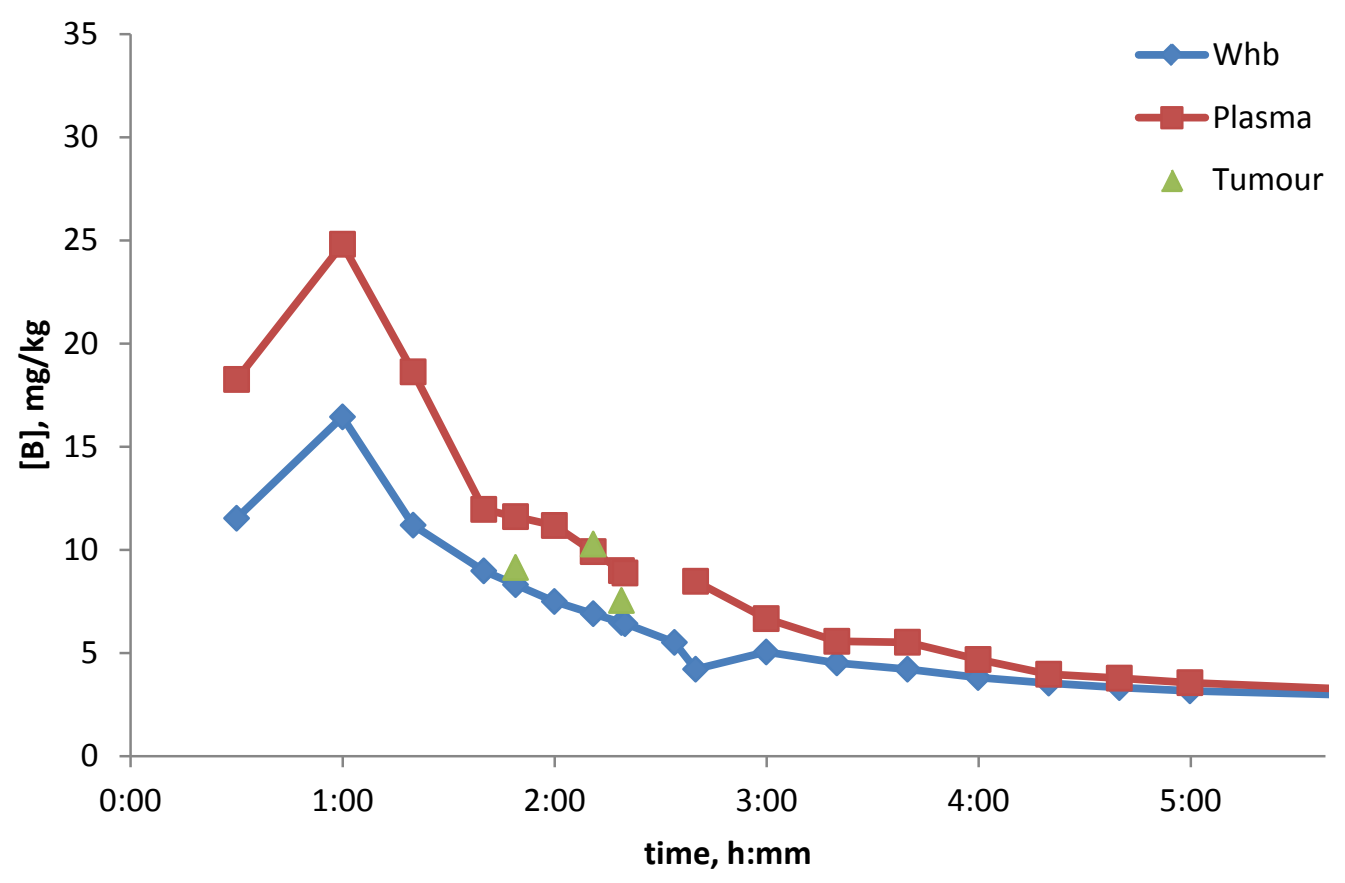

1.f.

Patient 7, schwannoma

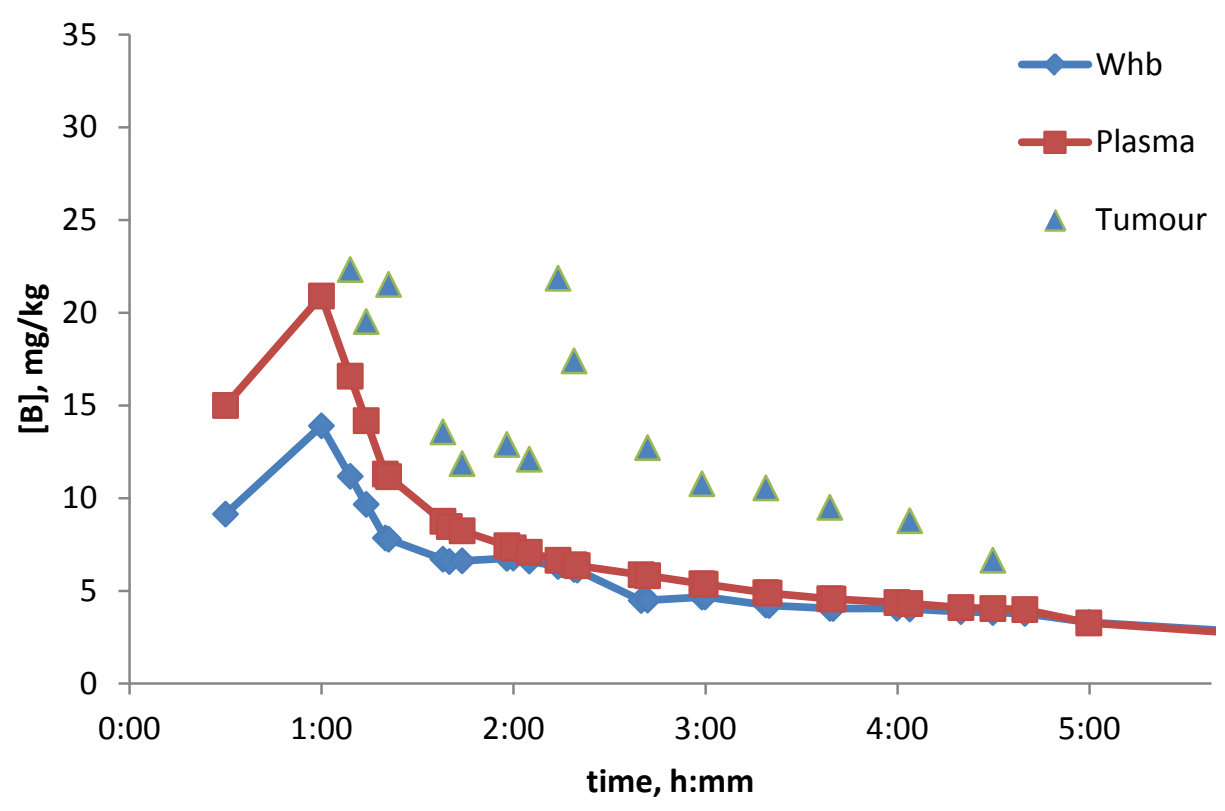

1.g. 


\section{Patient 8, schwannoma (NF2)}

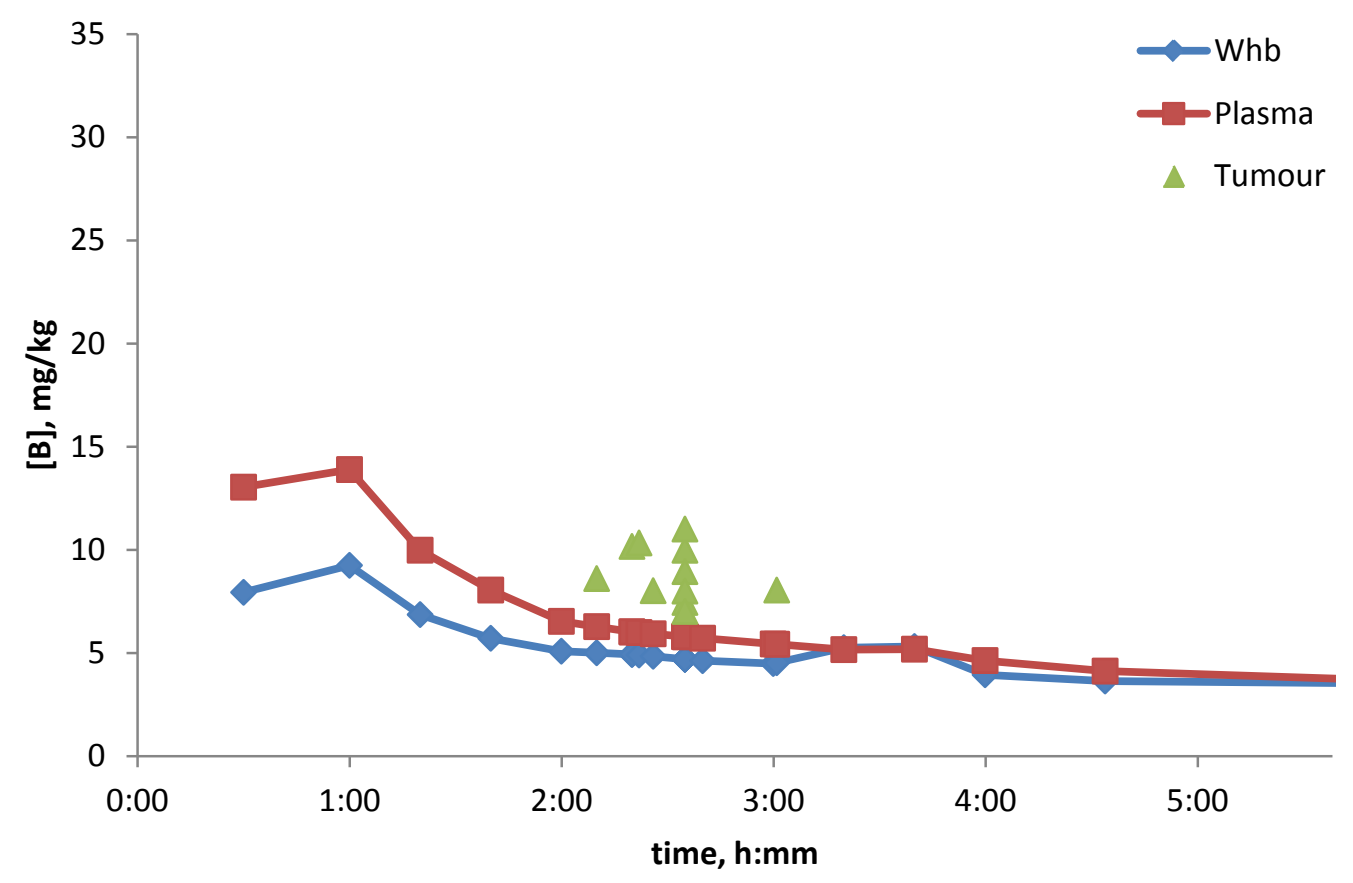

1.h.

Figures 1a to $1 \mathrm{~h}$. Boron concentrations in whole blood (blue diamonds), plasma (red squares) and tumour tissue (green triangles) as a function of time from onset of infusion.

Legend: 1.a: Patient 1, 1.b: Patient 2, 1.c: Patient 3, 1.d: Patient 4, 1.e: Patient 5, 1.f: Patient 6, 1.g: Patient 7, and 1.f: Patient 8 (also see Table 1), Whb: whole blood, Tumour: tumour tissue

To predict tumour to whole blood ratios based on all of our gathered data, we performed regression model analyses with the data with tumour-to-whole blood, tumour-to-plasma and plasma-to-whole blood ratios as the dependent variables and eight independent variables: dose per lean body weight (LBW), haematocrit, creatinine, estimated glomerular filtration rate (eGFR), tumour type, tissue sample location and age (Table 2). All dependent variables yielded a statistically significant constant. Dose per LBW, creatinine, eGFR and age proved statistically significant. The independent time variable (time in log minutes) was statistically significant for the plasma to whole blood ratio and negligible and statistically non-significant for the ratio of tumour to plasma. These findings will be further discussed below.

Table 2: Results of regression analysis using tumour-to-whole blood, tumour-to-plasma and plasma-to-whole blood ratios as dependent variables

\section{Ratio}

Tumour to Whole blood
Ratio Tumour to Plasma
Ratio

Plasma to Whole blood 


\begin{tabular}{|c|c|c|c|}
\hline $\mathrm{R}$ Square & 0.327 & 0.381 & 0.690 \\
\hline Adjusted R Square & 0.229 & 0.291 & 0.679 \\
\hline Number of observations & 72 & 72 & 180 \\
\hline F-test & $3.340^{\star * *}$ & $4.241^{\star \star *}$ & $67.642^{\star \star \star}$ \\
\hline Variable & beta & beta & beta \\
\hline Constant & $\begin{array}{r}21.824^{\star * *} \\
(6.218)\end{array}$ & $\begin{array}{r}25.252^{* * *} \\
(5.145)\end{array}$ & $\begin{array}{r}-5.459^{* \star \star} \\
(0.645)\end{array}$ \\
\hline Time in log minutes & $\begin{array}{c}-0.532^{*} \\
(0.269)\end{array}$ & $\begin{array}{r}-0.028 \\
(0.223)\end{array}$ & $\begin{array}{r}-0.298^{\star * \star} \\
(0.017)\end{array}$ \\
\hline Dose per LBW & $\begin{array}{c}-0.057^{* *} \\
(0.0 .024)\end{array}$ & $\begin{array}{r}-0.072^{* * *} \\
(0.020)\end{array}$ & $\begin{array}{r}0.024^{* * \star} \\
(0.002)\end{array}$ \\
\hline Haematocrit & $\begin{array}{c}0.105^{*} \\
(0.062)\end{array}$ & $\begin{array}{r}0.075 \\
(0.051)\end{array}$ & $\begin{array}{r}0.000 \\
(0.007)\end{array}$ \\
\hline Creatinine & $\begin{array}{r}-0.130^{* *} \\
(0.050)\end{array}$ & $\begin{array}{r}-0.145^{\star * *} \\
(0.041)\end{array}$ & $\begin{array}{r}0.033^{* * *} \\
(0.005)\end{array}$ \\
\hline eGFR & $\begin{array}{r}-0.049^{\star \star} \\
(0.021)\end{array}$ & $\begin{array}{r}-0.069^{* * *} \\
(0.018)\end{array}$ & $\begin{array}{r}0.027^{\star \star \star} \\
(0.002)\end{array}$ \\
\hline Meningioma & $\begin{array}{r}-0.476 \\
(0.405)\end{array}$ & $\begin{array}{r}-0.834^{\star *} \\
(0.335)\end{array}$ & $\begin{array}{r}0.256^{* * \star} \\
(0.044)\end{array}$ \\
\hline Stem & $\begin{array}{r}0.310 \\
(0.356)\end{array}$ & $\begin{array}{r}0.210 \\
(0.295)\end{array}$ & $\begin{array}{r}0.027 \\
(0.056)\end{array}$ \\
\hline Centre & $\begin{array}{r}0.278 \\
(0.356)\end{array}$ & $\begin{array}{r}0.185 \\
(0.295)\end{array}$ & $\begin{array}{r}0.027 \\
(0.056)\end{array}$ \\
\hline Age & $\begin{array}{l}0.024^{* *} \\
(0.010)\end{array}$ & $\begin{array}{r}0.024^{\star * *} \\
(0.008)\end{array}$ & $\begin{array}{c}-0.003^{* *} \\
(0.001)\end{array}$ \\
\hline
\end{tabular}

Legend: Standard errors in parentheses. Asterisk labels $\left(^{*}\right)$ stand for the level of statistical risk of rejecting the null hypothesis (beta $=0)$ incorrect: $(*) 10$ percent, $(* *) 5$ percent, $(* * *) 1$ percent risk level.

\section{Discussion and conclusions}

The uptake and distribution of boron has been modelled in several PET studies, both in malignant and benign CNS tumours (Havu-Auren et al., 2007; Imahori et al., 1998a, b; Kubota et al., 1996; Nuutinen et al., 2000; Nyberg et al., 1997). However, the only validated method for quantitative measurement of boron in tumours is by direct sampling, as was used in the present study. Direct sampling results of boron uptake in meningiomas and schwannomas have not previously been published.

In $\mathrm{BNCT}$, the desired radiation is directly proportional to the concentration of boron in the tumour. Based on our measurements of the true concentrations of boron in the tumour target, we consider BNCT feasible for selected meningiomas and schwannomas; the tumour to whole blood boron concentration ratios in meningiomas and schwannomas were between 2:1 and 6:1. 
The use of whole blood boron determinations in BNCT dosimetric calculations is supported by positron emission tomography (PET) studies on 18F labelled BPA, which have suggested that the plasma to whole blood boron concentration ratio of BPA is constant and close to 1.3 during and after the infusion of BPA-F (Imahori et al., 1998a, b). The experimental setting in these PET studies is, however, quite different from clinical studies. The dose in PET studies is minute, and the whole amount is administered as one single bolus injection. Moreover, it has also been claimed that patient' haematocrit is a major pre-analytical confounding variable in whole blood boron determinations (Laakso et al., 2001).

We controlled for the confounding effects of haematocrit variations by analysing the boron concentrations both from plasma and whole blood and then introducing a haematocrit variable to the statistical analysis (Table 2). Our results showed that the ratio of boron concentrations between whole blood and plasma varied with time after the onset of infusion. This seems to support our earlier claim that patient haematocrit, depicting mainly the proportion of erythrocytes in the blood, is a major pre-analytical confounding variable in whole blood boron determinations. Initially, the boron is in the plasma fraction only, but with time the red blood cells retain increasing amounts of boron (Kulvik et al., 2004; Laakso et al., 2001). Furthermore, as BPA probably behaves like phenylalanine, erythrocyte BPA might not be available for transport into tissues (Ellison and Pardridge, 1990; Kulvik et al., 2004).

The change in the plasma to whole blood ratio over time was statistically significant, whereas no evidence of change over time could be found for the ratio of tumour to plasma (Table 2). Hence, it could be meaningful to monitor boron concentrations from the plasma fraction in addition to, or even instead of, monitoring whole blood boron levels. As BPA was dosed per LBW, creatinine, eGFR and age showed statistical significance in our regression model. It might also be worthwhile to include these as parameters in BPA kinetics modelling and personalized dose optimization.

Although the possible implication of our findings for treatment planning goes beyond the scope of this paper, it will be discussed in a separate paper by Koivunoro et al. in this issue. Likewise, the combination of BPA with other boron carriers has not been addressed in our study but may prove essential for a truly effective BNCT. 
In our study, the variations both within the tumour and between tumours were large. As indicated earlier, all study samples showed a uniform histological appearance within the same tumour, whereby no significant variability in tissue boron concentration should be present as the result of tissue heterogeneity.

High variation in boron concentrations can result from within-day and between-day imprecision inherent to the analytical method, or from pre-analytical factors. While the imprecisions of the method have been reported earlier (Laakso et al., 2001; Linko et al., 2008), the latter sources of variance have not been fully evaluated and include the following:

- the blood flow to the tumour can be altered as a result of manipulation during the neurosurgical operation;

- rinsing of the tumour area with sterile solutions can have a washing effect on the boron;

- the samples can be extremely small and therefore some drying can occur, leading to higher boron concentrations per unit weight; and

- the use of cauterization can damage the sample tissue.

Our boron analysis methods in themselves are reliable and valid in the conventional error range (Laakso et al., 2001). To control for potentially confounding effects stemming from the operation procedure, whenever feasible we analysed samples that had not been intensively rinsed and that were as intact as possible. For the statistical analysis of the results, we introduced controls for both the size and the distance from the main blood vessel. These latter variables revealed no indication of systematic errors in the sampling procedure.

As life-expectancy has increased most notably in Western societies, more elderly meningioma or schwannoma patients will require therapy as a larger proportion of tumours in the elderly are inoperable. There is also an increasing number of surviving NF2 patients due to improved diagnostics and operating techniques. Despite NF2 patients' young age, the tumour development ultimately renders these patients untreatable. Hence, there is a growing need for symptom control.

Occasionally, it would be sufficient if the tumour could be made smaller or the growth arrested even if total removal was not possible. Stereotactic radiotherapy has been employed for this purpose in meningiomas and schwannomas in sporadic and in NF2 patients. 
As meningiomas and schwannomas are very radioresistant, conventional low linear energy transfer (low-LET) radiotherapy has only limited value for symptom relief. As BNCT yields high LET radiation, it is more effective for even slowly growing tumours, such as meningiomas and schwannomas. The minimum estimated required boron concentration suggested, $2 \mathrm{mM}$ or 100 $\mathrm{mg} / \mathrm{kg}$, seems within reach, even with current boron carriers by increasing the amounts of BPA infused (Linz, 2008). With successful BNCT, the unwanted dose to normal tissue remains low. Consequently, the development of BNCT for these tumours is warranted, especially as tumour shrinkage or even growth arrest can lead to sufficient symptom control for these histologically benign tumours.

\section{Acknowledgements}

This work was sponsored by the Department of the Army (Grant No. DAMD17-00-1-0545). The U.S. Army Medical Research Acquisition Activity, 820 Chandler Street, Fort Detrick MD 217025014, USA, is the awarding and administering acquisition office. We also express our sincere thanks to Dr Lauri Soinne for his valuable contribution.

\section{References}

Coderre, J.A., Chanana, A.D., Joel, D.D., Elowitz, E.H., Micca, P.L., Nawrocky, M.M., Chadha, M., Gebbers, J.O., Shady, M., Peress, N.S., Slatkin, D.N., 1998. Biodistribution of boronophenylalanine in patients with glioblastoma multiforme: Boron concentration correlates with tumor cellularity. Radiation Research 149, 163-170.

Ellison, S., Pardridge, W.M., 1990. Red cell phenylalanine is not available for transport through the blood-brain barrier. Neurochem Res 15, 769-772.

Gupta, N., Gahbauer, R.A., Blue, T.E., Albertson, B., 2003. Common challenges and problems in clinical trials of boron neutron capture therapy of brain tumors. J Neurooncol 62, 197-210.

Havu-Auren, K., Kiiski, J., Lehtio, K., Eskola, O., Kulvik, M., Vuorinen, V., Oikonen, V., Vahatalo, J., Jaaskelainen, J., Minn, H., 2007. Uptake of 4-borono-2-[18F]fluoro-L-phenylalanine in sporadic and neurofibromatosis 2-related schwannoma and meningioma studied with PET. Eur J Nucl Med Mol Imaging 34, 87-94.

Imahori, Y., Ueda, S., Ohmori, Y., Sakae, K., Kusuki, T., Kobayashi, T., Takagaki, M., Ono, K., Ido, T., Fujii, R., 1998a. Positron emission tomography-based boron neutron capture therapy using boronophenylalanine for high-grade gliomas: part I. Clinical cancer research : an official journal of the American Association for Cancer Research 4, 1825 1832.

Imahori, Y., Ueda, S., Ohmori, Y., Sakae, K., Kusuki, T., Kobayashi, T., Takagaki, M., Ono, K., Ido, T., Fujii, R., 1998b. Positron emission tomography-based boron neutron capture therapy using boronophenylalanine for high-grade gliomas: part II. Clinical cancer research : an official journal of the American Association for Cancer Research 4, 18331841 .

Kankaanranta, L., Seppala, T., Koivunoro, H., Saarilahti, K., Atula, T., Collan, J., Salli, E., Kortesniemi, M., UusiSimola, J., Valimaki, P., Makitie, A., Seppanen, M., Minn, H., Revitzer, H., Kouri, M., Kotiluoto, P., Seren, T., Auterinen, I., Savolainen, S., Joensuu, H., 2011a. Boron Neutron Capture Therapy in the Treatment of Locally Recurred Head-and-Neck Cancer: Final Analysis of a Phase I/II Trial. Int J Radiat Oncol Biol Phys.

Kankaanranta, L., Seppala, T., Koivunoro, H., Valimaki, P., Beule, A., Collan, J., Kortesniemi, M., Uusi-Simola, J., Kotiluoto, P., Auterinen, I., Seren, T., Paetau, A., Saarilahti, K., Savolainen, S., Joensuu, H., 2011b. Lboronophenylalanine-mediated boron neutron capture therapy for malignant glioma progressing after external beam radiation therapy: a Phase I study. Int J Radiat Oncol Biol Phys 80, 369-376.

Kubota, K., Ishiwata, K., Kubota, R., Yamada, S., Takahashi, J., Abe, Y., Fukuda, H., Ido, T., 1996. Feasibility of fluorine-18-fluorophenylalanine for tumor imaging compared with carbon-11-L-methionine. J Nucl Med 37, $320-325$. 
Kulvik, M., Vahatalo, J., Buchar, E., Farkkila, M., Jarviluoma, E., Jaaskelainen, J., Kriz, O., Laakso, J., Rasilainen, M., Ruokonen, I., Kallio, M., 2003. Clinical implementation of 4-dihydroxyborylphenylalanine synthesised by an asymmetric pathway. Eur J Pharm Sci 18, 155-163.

Kulvik, M.E., Vahatalo, J.K., Benczik, J., Snellman, M., Laakso, J., Hermans, R., Jarviluoma, E., Rasilainen, M., Farkkila, M., Kallio, M.E., 2004. Boron biodistribution in beagles after intravenous infusion of 4dihydroxyborylphenylalanine-fructose complex. Appl Radiat Isot 61, 975-979.

Laakso, J., Kulvik, M., Ruokonen, I., Vähätalo, J., Zilliacus, R., Färkkilä, M., Kallio, M., 2001. Atomic Emission Method for Total Boron in Blood during Neutron-Capture Therapy. Clinical Chemistry 47, 1796-1803.

Laakso, J., Ruokonen, I., Lapatto, R., Kallio, M., 2003. Inborn errors in metabolism and 4-boronophenylalaninefructose-based boron neutron capture therapy. Radiat Res 160, 606-609.

Laramore, G.E., Spence, A.M., 1996. Boron neutron capture therapy (BNCT) for high-grade gliomas of the brain: a cautionary note. Int J Radiat Oncol Biol Phys 36, 241-246.

Linko, S., Revitzer, H., Zilliacus, R., Kortesniemi, M., Kouri, M., Savolainen, S., 2008. Boron detection from blood samples by ICP-AES and ICP-MS during boron neutron capture therapy. Scandinavian Journal of Clinical \& Laboratory Investigation 68, 696-702.

Linz, U., 2008. Boron Neutron Capture Therapy for Glioblastoma: Is it Worth Pursuing? Technol Cancer Res Treat 7 , 83-88.

Locher, G., 1936. Biological effects and therapeutic possibilities of neutrons. Am J Roentgenol 36, 1-13.

Nuutinen, J., Sonninen, P., Lehikoinen, P., Sutinen, E., Valavaara, R., Eronen, E., Norrgard, S., Kulmala, J., Teras, M., Minn, H., 2000. Radiotherapy treatment planning and long-term follow-up with [(11)C]methionine PET in patients with low-grade astrocytoma. Int J Radiat Oncol Biol Phys 48, 43-52.

Nyberg, G., Bergstrom, M., Enblad, P., Lilja, A., Muhr, C., Langstrom, B., 1997. PET-methionine of skull base neuromas and meningiomas. Acta Otolaryngol 117, 482-489.

Philippon, J., 2003. [Operability of intracranial meningiomas]. Bull Acad Natl Med 187, 591-598; discussion 598-600. Rogers, L., Mehta, M., 2007. Role of radiation therapy in treating intracranial meningiomas. Neurosurg Focus 23, E4. 